\title{
A case of recurrent non-small-cell lung carcinoma and paraneoplastic Cushing's syndrome
}

\author{
I. Noorlander ${ }^{a}$, J.W. Elte ${ }^{b}$, O.C. Manintveld ${ }^{b}$, K.G. Tournoy ${ }^{c}$, \\ M.M. Praet ${ }^{d}$, J.P. van Meerbeeck ${ }^{c}$, J.G. Aerts ${ }^{a, *}$
}

\author{
a Sint Franciscus Gasthuis, Department of Respiratory Diseases, Kleiweg 500, 3045 PM Rotterdam, \\ The Netherlands \\ b Sint Franciscus Gasthuis, Department of Internal Medicine, Rotterdam, The Netherlands \\ c Ghent University Hospital, Thoracic Oncology Unit, Ghent, Belgium \\ d Ghent University Hospital, Department of Pathology, Ghent, Belgium
}

Received 4 July 2005; received in revised form 24 August 2005; accepted 24 August 2005

\section{KEYWORDS}

Cushing;

Ectopic ACTH;

Non-small-cell lung

carcinoma

\begin{abstract}
Summary Secretion of ectopic adrenocorticotropic hormone (ACTH) with consequently Cushing's syndrome is a rare paraneoplastic phenomenon. It has been described in a variety of malignancies, like bronchial carcinoids, small-cell lung carcinoma, thymoma, pancreatic carcinoma and other. In many cases of suspected ectopic ACTH secretion, it is difficult to histologically or cytochemically confirm the diagnosis. We present a 63-year-old woman with a recurrent poorly differentiated squamous cell lung carcinoma with clinical and biochemical features consistent with ectopic Cushing's syndrome. Immunocytochemical staining confirmed the secretion of ACTH by tumour cells.

(c) 2005 Elsevier Ireland Ltd. All rights reserved.
\end{abstract}

\section{Introduction}

"The name of Harvey Cushing (1869-1939) was immortalized in the history of medicine, by his discovery, in 1912, of Cushing's disease, an endocrine syndrome caused by a malfunction of the pituitary gland. This discovery was described in detail in: The Pituitary Body and its Disorders [1].",

\footnotetext{
* Corresponding author. Tel.: +31 10 4616149; fax: +31 104612692 .

E-mail address: j.aerts@sfg.nl (J.G. Aerts).
}

Cushing's syndrome is characterized by truncal obesity, a 'buffalo hump' and/or 'moon face', purplish abdominal striae, ecchymoses and proximal myopathy, accompanied by non-specific symptoms like edema, hypertension, fatigability and weakness, hirsutism, hyperpigmentation and diabetes. The syndrome can be ACTH-independent due to autonomous glucocorticoid-secreting adrenocortical adenomas or carcinomas. However, in most cases Cushing's syndrome is ACTH-dependent. The aetiology is bilateral adrenal hyperplasia due to hypersecretion of pituitary ACTH or ectopic production of ACTH by a non-pituitary cause like malignancy, respectively called Cushing's disease and 
Cushing's syndrome. Numerous tumours have been reported to secrete ACTH, like bronchial carcinoids, thymoma, pancreatic malignancy and smallcell lung carcinomas (SCLC).

We present a patient with a previous history of non-small-cell lung carcinoma (NSCLC), typical features consistent with Cushing's syndrome and mediastinal lymphadenopathy on computerized tomography $(\mathrm{CT})$.

\section{Case report}

In March 2005, a 63-year-old woman presented in our hospital with progressive dyspnea. She had a history of previous poorly differentiated squamous cell lung carcinoma of the lower right lobe in June 2001. For this, she had a lobectomy in another hospital with pathological tumour-staging PT1NOMO. After the operation she had gradually gained $50 \mathrm{~kg}$ of weight, which she ascribed to cessation of smoking. In January 2005, the general practitioner diagnosed her with hypertension and diabetes.

At presentation, physical findings showed a Cushingoid appearance, with a moon face, buffalo hump and centripetal obesity. There were no signs of hirsutism or hyperpigmentation, nor where there abdominal striae or ecchymoses. There was pitting edema of the legs and some tachypnea. Blood pressure was elevated (RR 175/75 mmHg). Her medication included a potassium sparing diuretic combined with a loop diuretic to control hypertension and edema, a biguanide to control glucose-levels and inhalation-corticosteroids.

Initial laboratory evaluation revealed a severe hypokalemia $\left(\mathrm{K}^{+} 1.8 \mathrm{mmol} / \mathrm{l}\right.$, Ref. range 3.5-5.0) with normal sodium, magnesium and calcium-levels and a normal renal function. Arterial blood gas analysis revealed a metabolic alkalosis with hypoxemia $\left(\mathrm{pH}\right.$ 7.60; $\mathrm{BE}$ 17.1; $\mathrm{HCO}^{3-} 41.1 \mathrm{mmol} / \mathrm{l}$ (Ref. range $22-29), \mathrm{pO}_{2} 53.6 \mathrm{mmHg}(7.15 \mathrm{kPa})$ and $\mathrm{pCO}_{2}$ $40.0 \mathrm{mmHg}(5.33 \mathrm{kPa}))$.

She was treated with intravenous and oral potassium chloride and supplemental oxygen. The diuretics were temporarily discontinued, however a potassium-sparing diuretic had to be re-started because of increasing edema of the legs. Hypertension was treated by an angiotensin I-blocker, utilizing its potassium-sparing quality.

Further investigations revealed high $09: 00 \mathrm{~h}$ plasma cortisol (1.58 $\mu \mathrm{mol} / \mathrm{l}$, Ref. range $0.18-0.72)$ with loss of diurnal variation (midnight plasma cortisol $1.43 \mu \mathrm{mol} / \mathrm{l}$, Ref. range $<0.21$ ). Urinary free cortisol was also elevated $(12.16 \mu \mathrm{mol} / 24 \mathrm{~h}$, Ref. range $0.03-0.28 \mu \mathrm{mol} / 24 \mathrm{~h}$ ), and so were the plasma ACTH-level ( $223 \mathrm{ng} / \mathrm{l}$, Ref. range $7-50)$ and plasma renin activity level $(6.70 \mathrm{ng} / \mathrm{ml} / \mathrm{h}$, Ref. range $0.8-5.5)$. Serum cortisol failed to suppress following $1 \mathrm{mg}$ dexamethasone overnight (09:00 h cortisol $1.55 \mu \mathrm{mol} / \mathrm{l}$, Ref. range $<0.14)$. Magnetic resonance imaging (MRI) did not reveal adenomas of the pituitary gland, suggesting that our patient had ectopic ACTH syndrome (EAS).

To identify the source of the ectopic ACTHproduction while considering her previous history of a lung carcinoma, a thoracic CT-scan was made, which showed mediastinal lymphadenopathy. On the abdominal CT-scan, there were no signs of adrenal hyperplasia or adenoma. Subsequently bronchoscopy was performed which did not reveal abnormalities. Curved linear endoscopic ultrasound-guided fine-needle aspiration (EUS-FNA) was performed to biopsy the enlarged lymph nodes and cytological examination demonstrated poorly differentiated squamous cell carcinoma. Assuming the prior resected tumour in the lower right lobe to be the primary tumour, this lymph node can be regarded as N3. Immuno-cytochemical staining of this specimen was positive for the neuroendocrine marker CD56 and for ACTH, suggesting paraneoplastic Cushing's syndrome (Fig. 1).

The patient was treated with ketoconazole ( $400 \mathrm{mg}$ three times daily) and plasma cortisol levels decreased, as did the potassium-suppletion needed. She developed bacteraemia with Staphylococcus Aureus-species, originating from a contaminated intravenous catheter. After two weeks of antibiotic treatment, induction-chemotherapy for TxN3MO NSCLC was administered (Vinorelbin $25 \mathrm{mg} / \mathrm{m}^{2}$ and Cisplatin $80 \mathrm{mg} / \mathrm{m}^{2}$ ). Ten days later, she developed bilateral pulmonary embolisms for which low molecular weight heparin (LMWH) was started. The patient deceased 18 days after onset of chemotherapy. Post-mortem autopsy revealed multiple bilateral pulmonary embolisms as direct cause of death.

\section{Discussion}

In ACTH-dependent Cushing's syndrome $20-25 \%$ of cases are caused by ectopic ACTH syndrome (EAS). It is well known that several lung tumours like bronchial carcinoids and small cell lung carcinoma are associated with EAS in approximately $1-5 \%$ of cases [2,3]. In recent literature, bronchial carcinoids seem to be the predominant cause of EAS, while the incidence of SCLC associated with EAS seems to decrease [9]. A possible explanation for this might be the declining incidence of SCLC, apart 

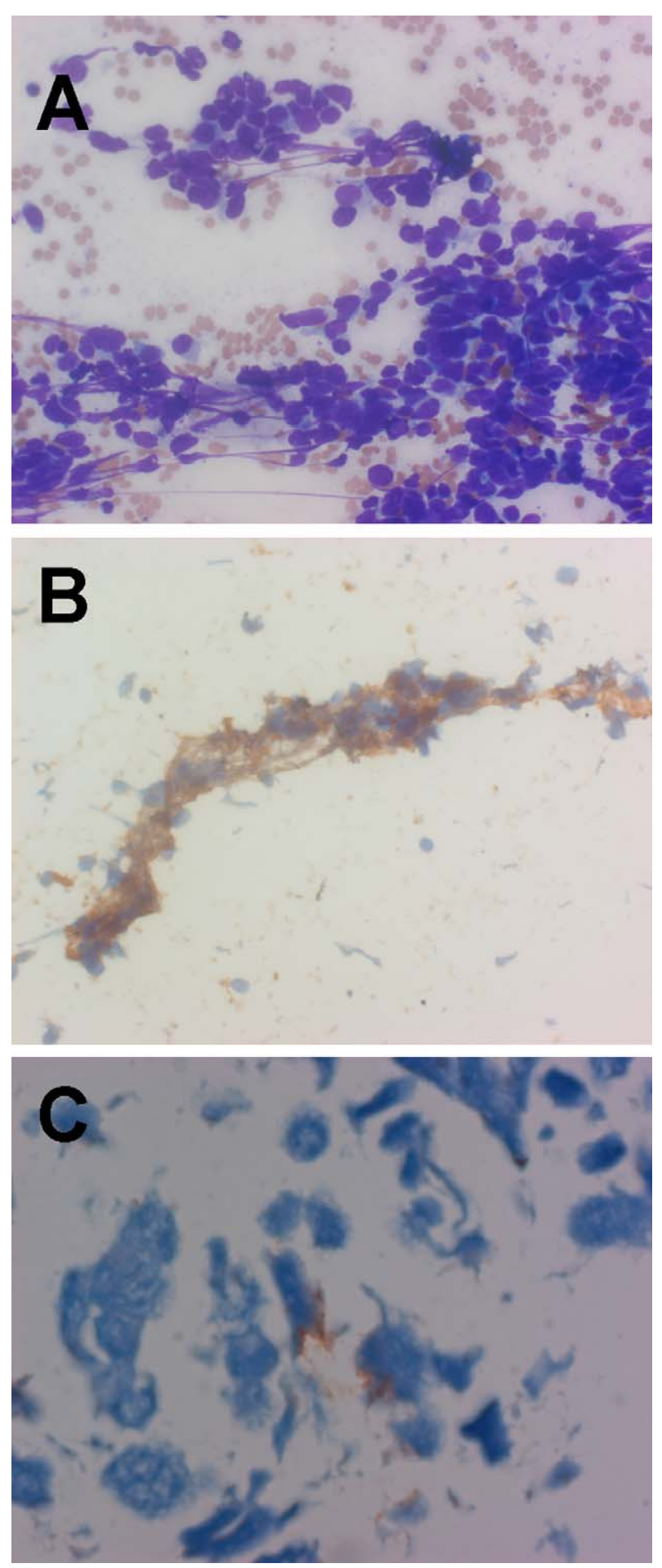

Fig. 1 Microscopy. (A) Giemsa Stain $(200 \times)$ : EUS-FNA reveals numerous neoplastic cells with anaplastic nuclei. (B) Immunocytochemistry with CD56 (200x): decoration of the neoplastic cells with CD56. (C) Immunocytochemistry with ACTH $(1000 \times)$ : some neoplastic cells express ACTH. from the fact that SCLC associated with Cushing's syndrome will be less reported due to the known association.

A non-small cell lung carcinoma causing ACTHdependent Cushing's syndrome has been seldom reported. In 1975, Imura et al. [4] reported three patients with adenocarcinoma of the lung, three patients with undifferentiated lungcarcinoma and one patient with a squamous cell carcinoma of the lung, which were all accompanied by ectopic ACTH secretion. However, these patients had no clinical signs of Cushing's syndrome. Since then, only four case-reports of NSCLC associated with EAS have been published [5-8]. In two of these cases, the diagnosis EAS could not be confirmed by tumour cell staining for ACTH or ACTH-precursors $[7,8]$. In the present case, however, the cytological material obtained stains for ACTH. Revision of the initial pathology specimens of 2001 showed no ACTH-expression by tumour cells at that time. It is known that tumour-relapses can show further dedifferentiation while developing neuro-endocrine features such as ACTH-secretion. For squamous cell carcinoma this is seldom seen.

All variables strongly support paraneoplastic type of Cushing's syndrome in this patient rather than a pituitary one. The existence of a lung carcinoma with positive immunocytochemical staining for ACTH is the most important observation. Furthermore, a severe hypokalemic alkalosis is common in EAS and is found in $71-100 \%$ of cases of ectopic ACTH secretion, but only in $10 \%$ of cases of pituitary ACTH syndrome [9]. Serum ACTHlevels were markedly elevated and levels above $200 \mu \mathrm{mol} / \mathrm{l}$, as in our patient, are rare in pituitary Cushing's syndrome. To exclude other causes of Cushing's syndrome, MRI of the pituitary gland was performed. Although no micro-adenoma was observed, it is reported that about $50 \%$ of pituitary micro-adenomas cannot be detected by MRI [21]. Unfortunately, obduction of the brain was not permitted by the relatives of the deceased. Inferior petrosal sinus ACTH sampling may be important in distinguishing between pituitary and ectopic ACTHproduction [10]. In our case however, this sampling was not performed because delay in inhibiting cortisol-production with ketoconazole would negatively influence the primary outcome. Furthermore, delay could be regarded unethical because of the finding of ACTH-positive cells by cytochemical staining.

The ultimate manner to control paraneoplastic ACTH syndrome is dependent on successful treatment of the primary tumour. There are several reports about the complications of chemotherapy in patients with ectopic ACTH-production. The com- 
plications reported are mostly related to severe infections and gastrointestinal bleeding or ulceration $[10,11]$. A small study of Dimopoulos et al. [12] reported nine out of 11 patients with SCLC and paraneoplastic Cushing's syndrome to decease within two weeks after onset of chemotherapy. Shepherd et al. [11] found that ectopic ACTHproduction is associated with a low response to chemotherapy, short survival and a high rate of complication.

Ketoconazole is used in the treatment of Cushing's syndrome, as it primarily inhibits CYP11B1 (11- $\beta$-hydroxylase) but also CYP11A1 (desmolase, cholesterol side-chain cleavage enzyme) in the adrenals. 11- $\beta$-hydroxylase is the enzyme responsible for the hydroxylation of 11-deoxycortisol to cortisol while desmolase converts cholesterol to $\delta$-5-pregnenolone [13-15]. Only a few reports about the usefulness of glucosteroid biosynthesis inhibitors in ectopic ACTH syndrome are published, and they report controversial results [16-20]. In the study of Winquist et al., the conclusions were that ketoconazole did not prolong survival, but it did provide a palliative hormonal response in two third of patients. In our patient, after administration of high doses of ketoconazole $(400 \mathrm{mg}$ three times daily), serum cortisol-levels and subsequently hypokalemia were finally controlled.

The present patient died of recurrent bilateral pulmonary thrombo-embolisms despite treatment with LMWH. Both active malignancy and Cushing's syndrome are associated with a hypercoagulable state because of an increase in plasma clotting factors like Factor VIII and von Willebrand factor complex, and to an impairment of fibrinolytic capacity $[22,23]$. This could explain why our patient suffered recurrent pulmonary embolisms despite adequate anticoagulant treatment.

In conclusion, we believe this patient presented with a Cushing's syndrome paraneoplastic to a poorly differentiated squamous cell carcinoma of the lung. Although uncommon, ectopic Cushing's syndrome can also be found in NSCLC, and is associated with a worse prognosis due to severe complications.

\section{References}

[1] Sabbatini RME. The history of psychosurgery. Brain Mind Mag 1997.

[2] Delisle L, Boyer MJ, Warr D, Killinger D, Payne D, Yeoh $\mathrm{JL}$, et al. Ectopic corticotropin syndrome and small-cell carcinoma of the lung. Clinical features, outcome and complications. Arch Intern Med 1993;153(6):746-52.

[3] Amer KM, Ibrahim NB, Forrester-Wood CP, Saad RA, Scanlon $M$. Lung carcinoid related Cushing's syndrome: report of three cases and review of the literature. Postgrad Med J 2001;77(909):464-7.

[4] Imura H, Matsukura S, Yamamoto H, Hirata Y, Nakai Y. Studies on ectopic ACTH- producing tumors. II. Clinical and biochemical features of 30 cases. Cancer 1975;35(5): 1430-7.

[5] Myers EA, Hardman JM, Worsham GF, Eil C. Adenocarcinoma of the lung causing ectopic adrenocorticotropic hormone syndrome. Arch Intern Med 1982;142(7):1387-9.

[6] Schott R, Chaouat A, Tavernier M, Kessler R, Weitzenblum E. Paraneoplastic hypercorticism associated with a bronchial adenocarcinoma. Rev Mal Respir 1999;16(3):395-7.

[7] Boon ES, Leers MP, Tjwa MK. Ectopic Cushing's syndrome in a patient with squamous cell carcinoma of the lung due to CRF-like production. Monaldi Arch Chest Dis 1994;49(1):19-21.

[8] Yoh K, Kubota K, Nomura M, Niho S, Goto K, Ohmatsu H, et al. Cushing's syndrome associated with adenocarcinoma of the lung. Intern Med 2003;42(9):831-3.

[9] Wajchenberg BL, Mendonca BB, Liberman B, Pereira MA, Carneiro PC, Wakamatsu A, et al. Ectopic adrenocorticotropic hormone syndrome. Endocr Rev 1994;15(6):752-87.

[10] Terzolo M, Reimondo G, Ali A, Bovio S, Daffara F, Paccotti P, et al. Ectopic ACTH syndrome: molecular bases and clinical heterogeneity. Ann Oncol 2001;12(Suppl 2):S83-7.

[11] Shepherd FA, Laskey J, Evans WK, Goss PE, Johansen E, Khamsi F. Cushing's syndrome associated with ectopic corticotropin production and small-cell lung cancer. J Clin Oncol 1992;10(1):21-7.

[12] Dimopoulos MA, Fernandez JF, Samaan NA, Holoye PY, Vassilopoulou-Sellin R. Paraneoplastic Cushing's syndrome as an adverse prognostic factor in patients who die early with small cell lung cancer. Cancer 1992;69(1):66-71.

[13] Sonino N. The use of ketoconazole as an inhibitor of steroid production. N Engl J Med 1987;317(13):812-8.

[14] Loose DS, Kan PB, Hirst MA, Marcus RA, Feldman D. Ketoconazole blocks adrenal steroidogenesis by inhibiting cytochrome P450-dependent enzymes. J Clin Invest 1983;71(5):1495-9.

[15] Stalla GK, Stalla J, Huber M, Loeffler JP, Hollt V, von Werder $\mathrm{K}$, et al. Ketoconazole inhibits corticotropic cell function in vitro. Endocrinology 1988;122(2):618-23.

[16] Winquist EW, Laskey J, Crump M, Khamsi F, Shepherd FA. Ketoconazole in the management of paraneoplastic Cushing's syndrome secondary to ectopic adrenocorticotropin production. J Clin Oncol 1995;13(1):157-64.

[17] Farwell AP, Devlin JT, Stewart JA. Total suppression of cortisol excretion by ketoconazole in the therapy of the ectopic adrenocorticotropic hormone syndrome. Am J Med 1988;84(6):1063-6.

[18] Shepherd FA, Hoffert B, Evans WK, Emery G, Trachtenberg $\mathrm{J}$, Ketoconazole. Use in the treatment of ectopic adrenocorticotropic hormone production and Cushing's syndrome in small-cell lung cancer. Arch Intern Med 1985;145(5): 863-4.

[19] Kornely E, Schlaghecke R, Horster FA. Palliative therapy of an ectopic Cushing's syndrome due to a metastatic carcinoid tumor. Klin Wochenschr 1991;69(4):173-6.

[20] Tabarin A, Navarranne A, Guerin J, Corcuff JB, Parneix M, Roger P. Use of ketoconazole in the treatment of Cushing's disease and ectopic ACTH syndrome. Clin Endocrinol (Oxf) 1991;34(1):63-9.

[21] Puig J, Wagner A, Caballero A, Rodriguez-Espinosa J, Webb SM. Cost-effectiveness and accuracy of the tests used in the differential diagnosis of Cushing's syndrome. Pituitary 1999;1(2):125-32. 
[22] Boscaro M, Sonino N, Scarda A, Barzon L, Fallo F, Sartori MT, et al. Anticoagulant profylaxis markedly reduces trombo-embolic complications in Cushing's syndrome. Clin Endocrinol Metab 2002;87(8):3662-6.
[23] Gouin-Thibault I, Achkar A, Samama MM. The thrombophilic state in cancer patients. Acta Haematol 2001;106(1/2):33-42.

Available online at www.sciencedirect.com

science $\mathcal{W}$ Direct 